\title{
Changing standards revisited: children's awareness and knowledge of features of written standard English at ages 10-11
}

Article

Accepted Version

Lockwood, M. (2012) Changing standards revisited: children's awareness and knowledge of features of written standard English at ages 10-11. Changing English, 13 (1). pp. 17-28. ISSN 1358-684X doi:

https://doi.org/10.1080/13586840500523455 Available at https://centaur.reading.ac.uk/26289/

It is advisable to refer to the publisher's version if you intend to cite from the work. See Guidance on citing.

To link to this article DOI: http://dx.doi.org/10.1080/13586840500523455

Publisher: Taylor \& Francis

All outputs in CentAUR are protected by Intellectual Property Rights law, including copyright law. Copyright and IPR is retained by the creators or other copyright holders. Terms and conditions for use of this material are defined in the End User Agreement.

www.reading.ac.uk/centaur 
Central Archive at the University of Reading

Reading's research outputs online 


\section{Changing Standards Revisited: Children's Awareness and Knowledge of Features of Written Standard English at Ages 10-11}

\section{Michael Lockwood}

University of Reading, UK

In 2006, I published an article in Changing English where I presented data from longitudinal research into children's awareness and knowledge of written standard English (SE) and discussed issues surrounding these data. The research involved surveys of Year 6 pupils (ages 10-11) from two schools in the south of England which were carried out in the summer terms of 1999, 2002 and 2005. The same research instrument, a written questionnaire, was used in all three surveys. The first survey was partly prompted by the introduction of the National Literacy Strategy (NLS) into English primary schools at the start of the academic year 199899 and one of the motivations behind the continuing research was to consider the impact the NLS has had on levels of awareness and knowledge of written SE. My original article concluded that there was little evidence of a significant impact of the NLS on implicit levels of awareness of SE; in fact, six years after the first sample, there was a clear overall decrease in levels of awareness. The findings as regards explicit knowledge of concepts and their technical terms also provided no evidence of achievement of NLS teaching objectives.

In the summer term of 2010 I repeated the survey, prompted by the new UK government's announcement that the National Strategies, of which the NLS was a part, would come to an end in April 2011. This meant that 2009-10 would be the last full year in which the NLS or its successor programmes would function in English schools, which presented a timely 
opportunity to revisit the area of children's implicit and explicit understanding of written SE after twelve full years of national literacy programmes which set teaching and learning goals in this area.

\section{Background}

Readers are invited to consult the original article (Lockwood 2006) for a full review of the context surrounding the introduction of the NLS in 1988. I will confine myself here to tracing the development of the NLS in English primary schools since 2005, the date of the last survey discussed in the article.

A 'renewed' Primary Framework for Literacy for English schools was produced in 2006, with the same non-statutory status as the previous NLS, which it replaced. As far as the area of standard English and language variation was concerned, there were now far fewer learning objectives relating to this and most of them appeared within the strands for speaking and listening. Under the strands concerned with writing, there was now only one reference to SE in the objectives, which occurred in the strand dealing with sentence structure and punctuation: 'Use standard English confidently and consistently in formal writing, with awareness of the differences between spoken and written language structures'.

(http://nationalstrategies.standards.dcsf.gov.uk/primary/primaryframework).

Previously, teaching objectives relating to the features of written SE were included in the NLS Framework for Teaching (DfEE/QCA, 1999) at 'sentence level' from Year 2 through to Year 6. There was also a Glossary which defined the term SE at length, although this document was subject to significant criticism from linguists and educationalists due to its 
inaccuracy (Sealey 1999, Cajkler, 1999 and 2004, Wales, 2009). In the 'renewed' Framework for Literacy of 2006, the Glossary was no longer available.

Although there was therefore much less mention of standard English and language variation in the context of writing in the revised Framework for Literacy, in the period in question (2005-10) the National Curriculum (NC) for primary schools, the statutory curriculum document in England, remained unchanged and thus the requirement to make children aware of the features of SE and the differences between it and non-standard usage, including dialect forms, continued to be a legal requirement for schools in England. (DfEE/QCA, 1999, p.49, p.51 and p57)

\section{Literature Review}

The reader is again referred to the original article for references to literature by Honey (1997), Bex and Watts (1999), Milroy and Milroy (1999), Crowley (2003) and Crystal (2005) about the 'Standard English question' and the linguistic, cultural, political and educational debate surrounding it. Discussions specifically about the place of SE in the original NC and the political context of the time, by Cameron (1995) and others, are also reviewed there. In educational terms, the debate can be summed up in the following way: should language variation be taught through the NC as a means of teaching children SE, or should SE be taught as a means of children learning about language variation?

Since 2006, further empirical research has been conducted in the area of written SE and how it is taught and learned in schools. Black (2010) investigated NSE in General Certificate of Education students (age 16) in England, using an assessment instrument broadly based on that used in this author's previous and current research (Lockwood 2006). Black's survey of a much larger sample of 
older pupils found similarities and differences between her findings and my own. Similarities included 'some gender difference, though not large, in awareness of NSE'; a high awareness of NSE forms which consist of subject-verb agreement; and 'similar rates of identifying "gotten" as NSE' (Black 2010: 23). Differences, which may have been influenced by differing research design, sample size or the age of the pupils, included:

- Adverbial use of the adjective ('Come quick') was the least commonly recognised form of NSE in Black's survey, whereas in my own it was one of the most frequently recognised.

- 'Should of / could of' for 'should have / could have' were identified as NSE by a large majority $(80 \%)$ of Black's respondents, whereas an even larger majority $(92 \%)$ accepted it as standard in my study.

- 'Me and my dad / friend' was accepted as SE by another large majority in my study (86\%) but only a minority (43.5\%) in Black's (2010: 23$)$.

Black also found in the qualitative data from her survey that most of her respondents 'could not spontaneously deploy the term non-standard English', preferring 'slang', 'informal' or 'colloquial' English. They also commonly used negative terms such as 'bad' or 'poor', 'incorrect' or wrong' English, and occasionally used derogatory ones such as 'appalling/disgraceful/pathetic', 'chavvy', ‘common or lower class'. (2010: 20). As Black concludes: ‘Despite National Curriculum aspirations not to treat $\mathrm{SE}$ as the prestige version, the majority of respondents identified the language in the stimulus sentences as of an inferior type (2010: 24).

Godley et al (2007) also investigated 'language ideologies', defined as 'the explicit and implicit assumptions about language that teachers and students hold' (2007: 103). Their study took place in the context of a revival of explicit, traditional grammar teaching in the U.S. in response to the 
inclusion of written grammar assessment in the Scholastic Aptitude Test (SAT) . Godley et al's research revealed that these assessments, and the language curriculum, teaching materials and learning activities associated with them, all endorsed an ideology which assumed there was a single correct dialect, written standard English, and viewed other dialects such as African American English as incorrect. Godley et al used the term 'stigmatized dialects' to refer to these, rather than nonstandard dialects (p.104). Through a year-long ethnographic study of a grammar activity called the Daily Language Practice, widely used as preparation for the SAT, their research 'suggested that students' understanding of the grammar and conventions of written standard English did not improve significantly over the course of the school year' (p.122). Their research recommended that 'in order to help students master the dialects valued in mainstream academic, civic, and economic institutions', literacy educators needed to develop approaches which promoted a different language ideology, one that 'recognises language variation ... and students' existing knowledge about language' as valuable, rather than as representing a deficit which required`remediation (p.123).

Pauwels and Winter (2006), in a study of Australian teachers, showed how changes to SE usage, which may spread to future generations, can occur in teachers' and pupils' writing where teachers are either unaware of standard structures or override this knowledge because they wish to change language for purposes of wider social reform. Pauwels and Winter give the example of teachers' (particularly female teachers') 'substantial adoption of gender-inclusive alternatives to generic he with a clear preference for and tolerance of singular they in their own and their students' writing.' (2006: 128). This feature is explored as an example of the "potential conflict classroom teachers face in their dual roles as "guardians of grammar" and as "agents of social language reform"” (ibid).

The relationship between standard and non-standard varieties of English has also remained in the arena of public debate during the period since 2005. For example, recent additions to popular 
discussion of this topic, both taking an historical perspective, have been the very successful Evolving English exhibition at the British Library, curated by David Crystal, along with his accompanying book with the same title (Crystal 2010), and also Henry Hitchings' The Language Wars: A History of Proper English (2011).

\section{Research Questions}

The project reported on here tried to address the following specific research questions:

- Which features of written English are 10-11 year olds able to recognise as non-standard?

- Are they able to suggest SE alternatives for these non-standard features?

- What do they know about the technical terms 'accent', 'dialect', and 'standard English'?

- Are there differences between boys' and girls' awareness and knowledge?

- Are there variations over time?

- Are there variations between schools?

For the purposes of this project, 'awareness' of SE and NSE was defined as the implicit understanding children show through their own usage and through their recognition of features of written English used in meaningful contexts. 'Knowledge' was defined as children's explicit understanding of technical terms relating to standard English and language variation shown through their ability to define or exemplify these terms.

\section{Research methods}

\section{Sample}

The research involved pupils from two schools in the south of England, School A and School B. A sample of 100 pupils in Year 6 (ages 10-11) was surveyed by written questionnaire in the summer term of 2010, repeating previous surveys in the same schools in 1999, 2002 and 2005. The percentage 
of boys and girls was exactly the same in all four of the surveys and exactly the same questionnaire was used.

\section{Research Instruments and procedures for use}

The questionnaire (see Appendix) was based on a list of NSE forms used in young people's speech included as an appendix to Hudson and Holmes' study Children's Use of Spoken Standard English (1995: 18-21), with additions of my own based on 'the most common non-standard usages in England' listed in the NC. The questionnaire was in two parts. Part 1 presented pupils with a series of sentences each containing one or more non-standard features. They were asked to:

- Identify any non-standard features

- Substitute standard features

- Indicate if they thought the sentence did not need changing

The intention of this section of the questionnaire was to assess children's implicit awareness of standard and non-standard forms in use in written English. In some of the sentences, two or more alternative standard forms were possible as substitutions, for example haven't or don't have as well as have not for ain't in sentence 2. All possible SE variants were accepted, including those using contractions. The second part of the questionnaire asked the children to explain the meanings of the terms 'accent', 'dialect' and 'standard English'. The intention here was to assess children's explicit knowledge of technical terminology mentioned in the NC and NLS.

\section{Analysis}

The quantitative data from the 2010 questionnaires were analysed to calculate simple frequencies for:

- $\%$ of pupils identifying each of the features of NSE

- $\%$ of pupils able to supply or not supply SE alternatives 
- $\%$ of pupils able to define three key technical terms

- $\%$ of boys and girls identifying each of the features of NSE

- $\%$ of pupils at School A and School B identifying each of the features of NSE

- $\%$ of boys and girls at each school identifying each of the features of NSE

These frequencies were compared to corresponding data held for the previous three surveys.

\section{Research Findings}

Which features of written English are 10-11 year olds able to recognise as non-standard? The survey of 10-11 year olds in the summer term of 2010 confirmed some of the quantitative data about children's implicit awareness of SE from the previous surveys of 1999, 2002 and 2005. Table I shows that the five non-standard forms which the largest majority of the sample children in 2010 identified were the same as in the period 1999-2005, though in different rank order:

[Table I here]

Non-standard forms often cited as ones which children frequently use in speech and writing, such as ain't and the adverbial use of proper, were still identified as such by a high proportion of the sample, though recognition of ain't had declined markedly. The subject-verb agreement involved in the use of is and wasn't in the questionnaire, mentioned in the NC and NLS as a particular feature of nonstandard English, was also still identified by over three-quarters of the children. Nearly two-thirds of children continued to identify gotten as NSE (see Table I) but a substantial and growing minority of 35\% now accepted the American verb form as standard British English. 
Of the five NSE features that the majority of the 2010 sample accepted as standard, four were also accepted by the majority in 1999-2005, though again the order was slightly different, as shown in Table II:

[Table II here]

\section{Are they able to suggest SE alternatives for these non-standard features?}

Although recognition of some NSE features showed a decline, as above, more noticeable was the decline in the percentage of children able to supply an acceptable SE form, having recognised a feature as NSE. For all six of the NSE features in Table I above, the percentage of respondents supplying a SE form was less in 2010, often substantially so.

What do they know about the technical terms 'Accent', 'Dialect' and 'Standard English'? As previously, the 2010 survey investigated explicit knowledge about the terminology of language variation as well as implicit awareness. The quantitative data revealed that $58 \%$ of the sample overall knew what 'accent' was in the sense that they were able to define it satisfactorily in terms such as: 'the way you say or pronounce words' or more specifically: 'a type of voice depending on where you're from'. The 2010 figure was similar to the average of 56.3\% from the previous three surveys. As in the earlier surveys, there was still a tendency amongst a substantial minority of respondents to be disparaging about language variation and to equate the word accent with foreign accents, an 'up north accent' or with 'someone who speaks funny'.

In the 2010 survey, only one child in the whole sample was able to offer even a partial (and also slightly disparaging) definition of the term 'dialect': 'dialect is weird words like ain' $t$ '. This is similar to the previous surveys where the average was $1.6 \%$. The large majority simply did not know what a dialect was and could not explain or exemplify the term: there was a non-response rate of $71 \%$ to this question. 
The non-response rate for the question relating to the term 'standard English' in the 2010 survey, at $37 \%$, was half that for 'dialect'. Of those who responded, about $40 \%$ of the children overall (a similar figure to the previous surveys) were able to offer some kind of partial definition of the term 'standard English', though none was able to offer a completely satisfactory definition, compared to $2.7 \%$ in the three previous surveys. The most popular partial definition was along the lines of 'standard English is proper words and not slang'. Other attempts associated the term with accent: 'well spoken English', 'very posh words', 'when you have no accent where you live'. Some children associated the term 'standard' with assessment: 'when your English is perfect', 'good at English', 'the right English'. For others, the term implied 'average' or 'normal': 'average, up to standard, English', 'the way that a normal English person should speak'. Finally, there was an interpretation of 'standard' to mean 'basic': 'simple English words', 'basic English'.

\section{Are there differences between boys' and girls' awareness and knowledge?}

As with the previous surveys, there were substantial differences between girls' and boys' recognition of some NSE features, with girls overall showing higher levels of recognition of 17 out of the 19 features included. The closing of the gender gap over the years of the three previous surveys, reported in the original article, was not continued. In 2010 the gap between girls' and boys' awareness of NSE forms, averaged over all 19 features, widened from 4.4\% in 2005 to $7 \%$ in 2010 (see Table III). Both girls' and boys' performances had improved since 2005 , but girls' by substantially more $(6.1 \%$ compared to $3.5 \%$ ). Girls showed improved recognition of NSE for 14 features and decreased recognition for 5, compared to 2005; whereas boys' recognition increased for 12 features and declined for 7 .

\section{[Table III here]}

As far as explicit language knowledge was concerned, more girls overall in 2010 were able to give a satisfactory definition of 'accent': $63.8 \%$ compared to $48.6 \%$ for boys. However, there was no 
difference when it came to the terms 'dialect' or 'standard English' since no children, boys or girls, were able to offer a completely satisfactory definition of either term in 2010.

\section{Are there variations over time?}

An overall decline in the children's awareness of NSE features over the six years of the earlier surveys was one of the findings commented on in the original article. A comparison between the 1999 and 2005 figures for all 19 of the features present in the research instrument revealed an increased recognition of 8 of the features but a decrease in 11, and across all 19 features there was an average decrease of $4.3 \%$. This overall decline was also not continued in 2010: compared to 2005, there was an increased recognition of 12 of the features and a decrease for 6 , with one remaining exactly the same, and across all 19 features there was an average increased recognition of 5.2\% from the corresponding 2005 figure.

\section{Are there variations between schools?}

When the data were analysed by school (Table IV), it became clear that the increase since the 2005 survey in the overall average percentage of children identifying the NSE features was accounted for by the large rise in School A's performance, the more so since there was a smaller decline in the performance of School B. Having been more or less constant at just over $48 \%$ over the previous three surveys, School B has declined to 46\%, whereas School A, after a dip in 2005, has scored its highest overall percentage recognition of NSE since the surveys began.

\section{[Table IV here]}

Analysed further, the differences between schools in 2010 appear more powerful than gender differences in accounting for the overall increase in NSE feature recognition since 2005. Table V 
shows that boys at School A, whilst clearly outperformed by the girls, were well in advance of both girls and boys at School B. Both the boys and girls at School A scored their highest levels recorded in all four of the surveys. By contrast, the boys at School B recorded their lowest result in all four surveys and the girls their second worst.

[Table Vhere]

Although since the first survey in 1999 there had been an increasing difference in performance between both boys and girls at the two schools, this had narrowed in 2005 due to the improved performance of the boys at School B. However, in 2010 the difference between both boys and girls at School A had increased substantially to the highest level recorded in the four surveys.

\section{Discussion}

\section{Limits of the research}

The limitations of this project, acknowledged in the original article, remain: only two schools in one area of England were sampled and the research instrument used was limited in scope and could not be revised without losing continuity. However, these limits were constant throughout, so should have affected the findings in a consistent way over time. Any generalisations arising from the research, though, obviously still need to be treated with caution.

\section{Implicit Awareness}

Awareness of some non-standard features of children's speech and writing cited in the National Curriculum, for example ain't ('formation of negatives') and proper ('formation of adverbs'), continued to be high amongst the 10-11 year olds in this latest survey. This would continue to lend support to the hypothesis that if children use these features widely it is from choice, in order to achieve a deliberate effect through code-shifting, rather than from ignorance of SE usage in the case 
of the majority. However, in Black's survey of 16 year olds the 'adverbial use of the adjective' was, by contrast, the least commonly recognised form, suggesting age as an important factor in the acceptance of a feature such as proper as SE. Conversely, the failure of over 90\% of the 10-11 yearolds to identify of [have] as NSE continues to contrast with Black's finding (2010: 23) of an identification rate of $80 \%$ for this feature amongst her older respondents. The development in pupils' awareness of SE with increasing age does not therefore seem to be consistent.

The acceptance of the American SE form gotten by more than a third of the 10-11 year olds, an increase from the previous surveys, and the acceptance by a large, if slightly reduced, majority of the sample children of non-standard usages such as me and my, off of, beautifulest and pound suggest that the these may continue to be areas where British SE is changing.

An unexpected finding of the 2010 survey, as revealed in Table 1, was the decline in the percentage of children able to supply an acceptable SE form, having recognised a feature as NSE. This is in contrast to the increased overall percentage of children able to successfully identify NSE features. This finding may be a result of the questionnaire design, in that pupils may not have realised they should also give a SE form as well as indicate where a feature is NSE. However, the same questionnaire did not seem to lead to this misunderstanding in the previous surveys. The finding may suggest a lack of confidence by respondents in what was acceptable as SE, even though they were implicitly aware that a usage 'sounded wrong'. This might lend weight to the view that as SE is changing, pupils are increasingly unsure of their ground.

\section{Explicit Knowledge}

In 2010, there was no evidence of improvement from the previous surveys in children's knowledge of the key terms for describing language variation, 'accent', 'dialect' and 'standard English', or the 
concepts behind them. This was the case for both schools surveyed and for both boys and girls. As reported above, there was an increasing reluctance, particularly marked in the higher-achieving School A, for children to even attempt a definition of the latter two terms. This could again suggest a lack of confidence on the children's part in their explicit linguistic knowledge, even where their implicit awareness of SE / NSE differences was relatively acute.

Though an important technical term, which is used in the National Curriculum as the heading for sections of the Speaking and Listening and the Writing programmes of study, SE is, like dialect, a term that the overwhelming majority of children in the two survey schools still clearly either misunderstand or do not know. The most common misconception still was to define SE in terms of the inferiority of other language varieties, as mentioned in their findings by both Black (2010:24) and Godley et al (2007: 123). The finding suggest that teachers in these two schools are still not using the terms 'standard English' and 'dialect' with children or exploring through them the concept of language variety, despite their continuing presence in the NC programmes of study for Speaking and Listening at Key Stage 2 (ages 7-11).

\section{Socio-Economic Factors}

It was noted in the original article (Lockwood 2006) that both schools used in the project were classified as in line with the national average in respect of pupils' attainment in English according to inspection evidence and the Year 6 NC tests in 1999 and 2000, at the beginning of the surveys. This was one reason for choosing them as sample schools initially. In 2010, the NC test scores for the percentage of pupils achieving Level 4 or above in English (used as an official indicator of school standards) were very different: $83 \%$ for School A and 64\% for School B, compared to a national average of $81 \%$, making School B well below average and School A above average. 
Looking at the developments in the two schools between 2005 and 2010 in socio-economic terms, it can be seen that they have increasingly diverged, as reflected in their pupils' academic attainment in English. Using a conventional indicator of socio-economic factors within an educational context, School A had 5.6\% of its pupils eligible for free school meals (FSM) in the academic year 2009-10, compared to over twice as many at $14.5 \%$ for School B, according to Department for Education official statistics. This divergence is also revealed by evidence from the schools' inspectorate, Ofsted. An inspection report of 2007 notes of School B that: 'The proportion of pupils eligible for free school meals is above average.' In the same year, 2007, School A's inspection report states that the percentage of pupils eligible for free school meals is about half the national figure.

Another indicator commonly used to indicate socio-economic context, the percentage of children with Special Educational Needs (SEN), also shows a divergence. Official statistics reveal that whereas School A in 2009-10 had 7.6\% of pupils with statements of SEN, School B again had more than twice as many at $15.1 \%$. An overall picture of the comparative socio-economic status of the two schools can be gained by using the official UK government 'Indices of Deprivation' statistics for 2010. Calculated by school postcode, School B is seen by this measure to have a Total Deprivation score of 0.66 , exactly twice that of School A (http://neighbourhood.statistics.gov.uk/dissemination/).

Thus a hypothesis arising from the data about the two schools may be that social class is actually a more important factor than gender, certainly in terms of pupils' implicit awareness of written SE as revealed by usage, if not in terms of their explicit knowledge. The divergence between the two schools in respect of pupil attainment in $\mathrm{NC}$ tests and in terms of socio-economic indicators between 2005 and 2010 may account for the widening gap in overall levels of identification of NSE features revealed by my latest survey. 


\section{The impact of the NLS /PNS}

No evidence was found of any impact of the NLS, introduced in 1998-99, on the sample children's levels of implicit awareness or of explicit knowledge of NSE and SE in the surveys carried out between 1999 and 2005. In fact, in the 2005 survey, sampling children who had been taught under the NLS for six years (the whole of their primary education), there was evidence of an overall decrease in levels of awareness. In 2010, as stated above, there was an overall increase in the sample pupils' awareness of NSE, though not in their awareness of SE alternatives. However, as shown, this increase can be accounted for by the improved performance of both boys and girls in School A. Thus it is difficult to attribute the higher percentages of pupils recognising NSE features to the revised version of the NLS , the PNS Literacy Framework, introduced in 2006, since the effect is not constant between the schools, both of whom implemented it. It could also be argued that any effects of the PNS Framework would be more likely to be observed in an increase in explicit knowledge of technical terms or awareness of SE forms, however there is no evidence of this.

\section{Conclusion}

In my original article I referred to the tensions teachers can experience in their daily interactions with young people in being regarded as the upholders of 'standards' by language purists. Pauwels and Winter's research (2006: 128) involving Australian teachers also identified the "potential conflict classroom teachers face in their dual roles as "guardians of grammar" and as "agents of social language reform"”. These tensions may become more pronounced for teachers in England from September 2012 when the new 'Standards' for the award of Qualified Teacher Status (QTS) are adopted. For example, in the Standards for 'Teaching' in Part One it is stated that: 'A teacher must...:

- demonstrate an understanding of and take responsibility for promoting high standards of literacy, articulacy and the correct use of standard English, whatever the teacher's specialist subject.' 
(https://www.education.gov.uk/publications/standard/publicationDetail/Page1/DFE00066-2011)

The placing of SE within the context of language variation, incorporated in the present $\mathrm{NC}$, is quite absent here. In order to qualify as a teacher, it is necessary only to 'promote' an undefined and monolithic concept of 'correct use of standard English'. Research by Godley et al (2007) and Black (2010), referred to above, discussed the unexamined 'language ideology' behind this concept. The deficit model of language variation implied in this was found in many children's responses in my own research also.

This model may also be reinforced by the new NC test in writing which will be introduced for Year 6 (ages 10-11) pupils in English schools in 2013. This test is to assess the 'technical aspects of English', specifically spelling, grammar, punctuation and vocabulary, rather like the US Scholastic Aptitude Test in written grammar, with its attendant 'language ideology', investigated by Godley et al (2007) above.

The findings of my latest survey suggest the importance of socio-economic factors in determining children's awareness and knowledge of features of written standard English. If teachers are to be successful in giving more disadvantaged children access to standard varieties of English, research such as that by Godley et al (2007) suggests this cannot be done through reinforcing a deficit model of 'correct standard English', as demanded by the new QTS standards in England and the new NC test for' technical English', but requires that children's non-standard varieties are also valued and the 'standard' variety is seen as an 
addition to their linguistic repertoire not as a replacement for it. Rather than introduce a new $\mathrm{NC}$, as is currently proposed by the UK government, my research suggests that, in the area of standard English and language variation, what actually needs to happen is that the current NC should be properly implemented and supported instead. 
Appendix: the survey questionnaire (the 19 NSE features are italicised)

FIRST NAME

AGE

BOY / GIRL

Part 1: Are there any words in these sentences which don't sound right to you? If there are, please circle the words and write different ones underneath. If you think a sentence is $\mathrm{OK}$, give it a tick at the side:

1. He doesn't know nothing hisself.

2. We ain't got none.

3. We done our work proper.

4. I fell off of the wall.

5. That's the boy what I told you about.

6. I never seen nobody.

7. She was the beautifulest of the two women.

8. They wasn't late.

9. I could of told you the answer.

10. He's gotten into trouble.

11. Them books is interesting.

12. Me and my dad paid five pound to go up London.

Part 2: Do you know what the words below mean? Have a guess if you're not sure:

ACCENT

DIALECT 


\section{References}

Bex, T. and Watts, R.J.[eds] 1999. Standard English: the widening debate. London: Routledge.

Black, B. 2010. Exploring non-standard English amongst teenagers. Research Matters 9: 211.

Cajkler, W. 1999. Misconceptions in the NLS: National Literacy Strategy or No Linguistic Sense? Use of English 50, no. 3: 214-27.

Cajkler, W. 2004. How a dead butler was killed: the way English National Strategies maim grammatical parts. Language and Education 18, no.1: 1-16.

Cameron, Deborah. 1995. Verbal Hygiene. London: Routledge.

Crowley, T. 2003. Standard English and the politics of language. Basingstoke: Palgrave

Crystal, David. 2005. The stories of English. London: Penguin

Crystal, David. 2010. Evolving English: one language, many voices. London: The British Library.

Department for Education. Teachers' Standards. Department for Education. https://www.education.gov.uk/publications/standard/publicationDetail/Page1/DFE$\underline{00066-2011}$

Godley, A., Carpenter, B. \& Werner, C. 2007. 'I'll speak in proper slang': language ideologies in a daily editing activity. Reading Research Quarterly 42, no.1: 100-131.

Hitchings, Henry. 2011. The language wars: a history of proper English. London: John Murray. 
Honey, J. 1997. Language is power: the story of standard English and its enemies. London: Faber.

Hudson, R. 1998. Is grammar teachable? English 4-11. 2: 11-14.

Hudson, Richard and Holmes, Jasper. 1995. Children's use of spoken standard English. London: School Curriculum and Assessment Authority.

Lockwood, M. 2006. Changing standards? Children's awareness and knowledge of features of written standard English at ages 10-11. Changing English 13, no.1: 17-28.

Milroy,J. and Milroy, L. 1999. Authority in language: investigating standard English. $3^{\text {rd }}$ edition, London: Routledge.

Paterson, L. 2010. Grammar and the English National Curriculum. Language and Education 24, no.6: 473-84.

Pauwels, A. and Winter, J. 2006. Gender inclusivity or 'Grammar Rules OK'? Linguistic prescriptivism vs. linguistic discrimination in the classroom. Language and Education 20, no. 2: $128-40$.

Qualifications and Curriculum Authority. 1998. The grammar papers: perspectives on the teaching of grammar in the National Curriculum. London: Qualifications and Curriculum Authority.

Rose, J. 2009. Independent review of the primary curriculum: final report. London: Department for Children, Schools and Families.

Sealey, A. 1999. Teaching primary school children about the English language: a critique of current policy documents. Language Awareness 8, no.2: 84-97. 
Wales, L. 2009. Reviving the dead butler? Towards a review of aspects of national literacy strategy grammar advice. Language and Education 23, no.6: 523-39. 
Table I: the NSE forms most frequently identified

\begin{tabular}{|c|c|c|c|c|c|c|}
\hline $\begin{array}{l}\text { Rank } \\
\text { Order } \\
\text { (2010) }\end{array}$ & NSE form & SE form & $\begin{array}{l}\text { \% } \\
\text { Identified } \\
\text { NSE form } \\
2010\end{array}$ & $\begin{array}{l}\% \\
\text { Identified } \\
\text { NSE form } \\
1999-2005\end{array}$ & $\begin{array}{l}\text { \% } \\
\text { Supplied } \\
\text { SE form } \\
2010\end{array}$ & $\begin{array}{l}\% \\
\text { Supplied } \\
\text { SE form } \\
1999-2005\end{array}$ \\
\hline 1 & hisself & himself & 91 & 76 & 57 & 64 \\
\hline 2 & proper & properly & 80 & 82 & 57 & 70 \\
\hline 3 & wasn't & were not & 80 & 73 & 58 & 62 \\
\hline 4 & is & are & 77 & 78 & 59 & 72 \\
\hline 5 & ain't & have not & 74 & 89 & 61 & 80 \\
\hline $10=$ & gotten & got & 65 & 70 & 44 & 64 \\
\hline
\end{tabular}


Table II: the NSE forms most frequently accepted as standard

\begin{tabular}{|c|c|c|c|c|}
\hline $\begin{array}{l}\text { Rank } \\
\text { Order } \\
\text { (2010) }\end{array}$ & NSE form & SE form & $\begin{array}{l}\% \\
\text { Accepted } \\
\text { NSE form } \\
\text { as SE } \\
2010\end{array}$ & $\begin{array}{l}\% \\
\text { Accepted } \\
\text { NSE form } \\
\text { as SE } \\
1999-2005\end{array}$ \\
\hline 1 & $\begin{array}{l}\text { me and my } \\
\text { dad }\end{array}$ & $\begin{array}{l}\text { my dad / } \\
\text { father and } \\
\text { I }\end{array}$ & 91 & 86 \\
\hline 2 & could of & could have & 90 & 92 \\
\hline 3 & off of & off & 85 & 78 \\
\hline 4 & five pound & pounds & 66 & 80 \\
\hline 5 & none & any & 52 & 48 \\
\hline
\end{tabular}


Table III: overall average identification of NSE forms by year and gender

\begin{tabular}{|l|l|l|l|}
\hline & \% Boys & \% Girls & Girls Difference in \\
& & & \\
\hline 1999 & 50.2 & 61.5 & 11.3 \\
\hline 2002 & 53.8 & 55.6 & 1.8 \\
\hline 2005 & 49.9 & 54.3 & 4.4 \\
\hline 2010 & & & 7.0 \\
\hline
\end{tabular}


Table IV: overall average identification of NSE forms by year and school

\begin{tabular}{|l|l|l|l|l|}
\hline & 2010 & 2005 & 2002 & 1999 \\
\hline School A & 65.8 & 56.3 & 61.4 & 60.2 \\
\hline School B & 46.5 & & & \\
\hline \% identification & & 48.3 & 48.1 & 48.6 \\
\hline
\end{tabular}


Table V: overall average identification of NSE forms by gender, year and school

\begin{tabular}{|c|c|c|c|c|c|c|c|c|}
\hline & \multicolumn{2}{|l|}{2010} & \multicolumn{2}{|l|}{2005} & \multicolumn{2}{|l|}{2002} & \multicolumn{2}{|l|}{1999} \\
\hline & Girls & Boys & Girls & Boys & Girls & Boys & Girls & Boys \\
\hline $\begin{array}{l}\text { School A } \\
\% \text { identification }\end{array}$ & 68.3 & 61.3 & 60.6 & 49.2 & 61.8 & 61.3 & 65 & 56.1 \\
\hline $\begin{array}{l}\text { School B } \\
\% \text { identification }\end{array}$ & 48.7 & 42.8 & 46.5 & 50.4 & 49.2 & 46.6 & 55.9 & 44.2 \\
\hline $\begin{array}{l}\text { School A } \\
\text { difference in \% } \\
\text { from School B }\end{array}$ & +19.6 & +18.5 & +14.1 & -1.2 & +12.6 & +14.7 & +9.1 & +11.9 \\
\hline
\end{tabular}

